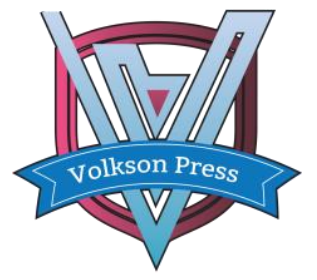

Contents List available at VOLKSON PRESS

Economics \& Management Innovations(EMI)

DOI : http://doi.org/10.26480/icemi.01.2017.231.232

\title{
The Problems and Countermeasures of Visually Impaired Students Integrating into Ordinary Universities
}

\section{Yang Shiqin, Ma Hui,}

College of Humanities and law, Wuhan University of Technology

2439604821@qq.com

This is an open access article distributed under the Creative Commons Attribution License, which permits unrestricted use, distribution, and reproduction in any medium, provided the original work is properly cited.

\section{ARTICLE DETAILS}

\section{Article History:}

Received 02 october 2017 Accepted 06 october 2017

Available online 11 october 2017

\section{Keywords:}

visually impaired students; ordinary university; integrated education; Integrated education, also known as inclusive education, is an advanced educational concept that emerged in the 1990s. It means that students with disabilities enter ordinary schools on the basis of equality and discrimination and are educated with healthy students. They get the support and help that they need from the school.

\section{ABSTRACT}

With the continuous development of higher integration education, more and more visually impaired students enter the ordinary universities to study, which means achieving a major improvement in education equality, but at the same time, how to integrate into college life for visually impaired students is extremely Worthy of attention. This paper points out and analyzes the problems in the process of integration into the university life for visually impaired students and puts forward practical suggestions to promote the healthy growth of visually impaired students in university study and life.

\section{Introduction}

In 1987, Changchun University Special Education College recruited blind students, which can be regarded as the beginning of higher special education for the visually impaired students in China. It was the implementation of the special education system of isolation education. Since 2003, Shanghai has begun to recruit visually impaired students in ordinary universities of higher learning. East China Normal University, Shanghai Normal University and other universities have received more than 10 visually impaired students. The newly revised Law on the Protection of Persons with Disabilities in 2008 stipulates that general education institutions shall educate persons with disabilities with general educational skills and provide assistance and help for their learning. In 2012,the "barrier-free environment construction regulations" was issued.It says that we should give priority to improve the barrier-free facilities in universities. In 2014, the Ministry of Education issued the notice that ordinary universities should do good jobs in the recruitment, which pointed out all kinds of examination institutions should provide people with disabilities with the equal registration in the examination.If the blind students are participated in the examination, examination institutions should provide blind papers ,Electronic papers or help by specialized staff for the blind candidates. " In 2015, the Ministry of Education and the China Disabled Persons 'Federation jointly issued the Provisions on the Administration of Disabled Persons' Entrance Examination for National Entrance Examination in Ordinary Colleges and Universities (Temporary). This was the first time that China made a management regulation for disabled people to participate in the general college entrance examination, which was also an opportunity and a challenge for visually impaired students.

Second, the problems of visually impaired students into ordinary colleges and universities

2014 was the first year that the blind students participated in the general college entrance examination, which was a effective way for the visually impaired students to accept the higher education and had a profound impact on China's special education system. Due to the inconvenience caused by the lack of vision, visually impaired students have some problems which can not be ignored in the process of integration into the general colleges and universities.

\section{(1) security issues}

Due to their own physical defects, the self-care ability of visually impaired students is lower than the sound students. They can not protect their own safety. The safety problems of the visually impaired students are mainly manifested in the following three aspects.

First, the problem is the campus public facilities. At present, most of ordinary colleges and universities in the school building construction and campus design did not consider the living needs of people with disabilities.The campus facilities are lack of accessibility. For example, there is no blind path for visually impaired students, and the production of various signs is not conducive to the identification and touch for visually impaired students. Second, compared with the sound of students, visually impaired students have more security risks in campus collective life, such as collide, crowded stampede, electricity safety, water safety and other issues. For example, visually impaired students may carelessly bruise themselves or others because of lack of vision.It is easy to burn themselves if hot water spills. Third, visually impaired students have a certain security risk in the experimental class and physical education classes and other practical classes,such as alcohol lamp ignition in experimental class, improper use of chemicals and sports injuries in sports class and so on.

(2) the issue of communication

After visually impaired students enter the general university, they will establish a new interpersonal circle, including geting along with the new teachers and new students.New students often come from different places with different habits and personality characteristics.How to get along with new students and how to show themselves confidently In front of the sound students is a knowledge which visually impaired students must master. It is not an easy thing 
for the visually impaired students. Because most visually impaired students have a sense of inferiority, they feel that they are not as good as sound college students in all aspects. Due to fear of being looked down upon, they rarely take the initiative to communicate with the students in a class,leading to enclosing themselves in a narrow world. In addition, the visually impaired students are more sensitive than the sound students, so they are often wary of the other students in the class. What is more, due to the lack of contact with the outside world, their abilities to accept new things and information are far behind the sound students. Sometimes it is difficult for visually impaired students to have the same interest with the sound students in a class. Over time, the visually impaired student's personality is more and more withdrawn and passive when getting along with people.

\section{(3) learning problems}

Learning efficiency of visually impaired students is not high in the process of accepting higher integration education. First, their learning methods are not appropriate. Although some visually impaired students have proper learning attitude and work hard, the effect is minimal. The reason is the problem of learning methods. Second, the visual barrier lead to slow reading, affecting learning. All blind students learn to read braille and the word speed is far lower than the sound students, which largely affected their learning efficiency. Low vision students have learning problems because they can not see or see the word slowly and other reasons. Third, the visually impaired student's learning base is weak and they are lack of learning ability. Although visually impaired students and healthy students are in a university classroom, because of visual impairment reasons, teachers reduce the requirements or even no demand for the visually impaired students.Over a period of time, they will be backward other students. Their weak foundation affects later learning,so learning efficiency is difficult for them to improve.

The imperfection of teaching facilities is also one of the difficulties in learning difficulties of visually impaired students. The teaching equipments of ordinary colleges and universities are purchased for the sound students, and the teaching supplies and auxiliary equipments needed by the visually impaired students are rarely bought. For example, ordinary colleges do not provide visual aids and expanders for visually impaired students and so on.

\section{Suggestions and Countermeasures}

First,we should improve the campus facilities. With the further development of higher integration education, considering the needs of visually impaired students and setting up the barrier-free facilities in the general colleges and universities is imperative. In addition, the construction of a variety of signs in the school should consider the following aspects, which are useful for visually impaired students to identify and touch.

One, a variety of signs, signboards, warning signs should be made larger, the color of signs and the color of the surrounding environment should have a eyecatching contrast. Evening light should be suitable for low vision students to find and identify signs .

Two, a variety of signs should be set in the appropriate location, visual card ought to be slightly higher.touch card should not be too high, and 1.1 --- 1.4 meters is the appropriate.

Three, the best thing is that sign on the plate can also set a bigger Chinese characters, so that it will make it easy for blind and low vision students to touch.

For, blind people can not know many words of touch signs located in the wall, so a notice should be made in the handrails which are below the Braille signs.

In the teaching facilities, ordinary colleges should take visually impaired students' learning need into consideration, buying those which are conducive to their learning equipments, such as blind plate, Braille writing paper and so on.

Second, it is very important to create a good campus atmosphere

On the one hand, the ordinary colleges should encourage visually impaired students to cultivate hobbies, including taking advantage of student associations, community organizations to organize rich extracurricular activities, such as knowledge contest, singing competition, etc,which are useful for promoting the enthusiasm of the visually impaired students. Students not only improve self-confidence, but also established a good interpersonal relationship and expand the circle of friends in the process of participating in activities. On the other hand, teachers should create a relaxed teaching atmosphere. If visually impaired students learn in a relaxed and enjoyable environment, they will improve greatly their learning enthusiasm and learning efficiency. In addition, teachers ought to treat visually impaired students on the basis of equality, patiently answer their questions, carefully analyze their learning errors, and enhance the teaching of the vivid and interesting, thus mobilizing the visually impaired students to study actively. What is more, teachers and students should work together to create a good atmosphere for visually impaired students. Teachers should encourage visually impaired students to communicate with other students, teach them interpersonal skills,and establish a harmonious relationship with visually impaired students. Sound students should take the initiative to care for visually impaired students, learn to get along well with them and make friends with them.

Third, it is of vital importance for visually impaired students to establish the campus safety self-care awareness

Safety education can not be ignored. Although schools and teachers attach great importance to the visually impaired students' safety, they are external factors. The most critical factor is to make the visually impaired students firmly establish the safety awareness and develop self-help ability. For example, teachers should educate the visually impaired students to develop safety awareness, and remind the visually impaired students of paying attention to the safety of every detail in the teaching process. Visually impaired students should be in accordance with the correct operating procedures to prevent the occurrence of classroom safety incidents. What is more, if an accident happens, visually impaired students should keep calm and ask others quickly to find school doctors and teachers to tell them their own injuries, and immediately call 120 emergency for treatment.

\section{Conclusion}

Visually impaired students face security problems, communication problems, learning problems and other aspects of the problem in the process of integration into the general colleges and universities, affecting their physical and mental health. Improving the campus facilities, creating a good campus atmosphere and establishing a awareness of self-care are effective ways to protect the visually impaired students and which are benefical for them with sound students to learn and live happily. Visually impaired students integrate into ordinary colleges and universities, which needs everyone's joint efforts.

\section{References:}

[1] Ma Yu. The development trend of higher integration education for the disabled [J]. Fujian: Strait Education Research .2013.1.

[2] Li Xuehui, Fu Zhijun. From isolation to integration [J]. Jiangxi: social work .2015.6.

[3] Zhang Lei, Xue Mei, Ge Yuping. Visually impaired students mental health education and counseling [M]. Tianjin: Tianjin Education Press .2013.9.

[4] Du Benyou, Zhang Lei, etc. Visually impaired students social adaptability training strategy and implementation [M]. Beijing: China Light Industry Press, 2015.

[5] Xiong Qi. The Development Course, Problems and Suggestions of Higher Education for the Disabled in China under the Idea of Integration [J]. Journal of Suihua University, 2016.36.

\section{[6] http://edu.qq.com/a/20151118/023587.htm}

\section{[7] http://edu.qq.com/a/20151118/023587.htm}

[8] http://www.chinadaily.com.cn/dfpd/dfjyzc/2012-0309/content_5364818.html

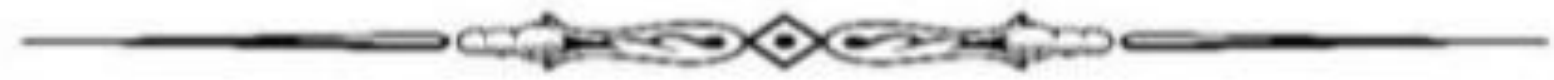

